\title{
APORTES DE LA BIOTECNOLOGÍA AL MEJORAMIENTO DEL ARROZ EN ECUADOR.
}

\section{CONTRIBUTIONS OF BIOTECHNOLOGY TO RICE IMPROVEMENT IN ECUADOR.}

Iris Betzaida Pérez Almeida, Ph.D.

Doctora en Filosofía en Botánica y Fitopatología (EEUU). Docente Tiempo Completo de la Facultad de Ingenierías de la Universidad Tecnológica ECOTEC, Ecuador. iperez@ecotec.edu.ec

\section{ARTÍCULO DE REVISIÓN BIBLIOGRÁFICA}

Recibido: 29 de julio de 2019.

Aceptado: 4 de septiembre de 2019.

\section{RESUMEN}

Este artículo tiene como objetivo realizar un balance de la aplicación de la biotecnología vegetal en la agricultura ecuatoriana, tomando como caso de estudio el cultivo del arroz. Se describen las técnicas más comúnmente utilizadas en Latinoamérica. Hasta ahora la mayor parte de la investigación en Ecuador ha estado enfocada al cultivo de tejidos (anteras); escasamente se ha trabajado en la caracterización del germoplasma de arroz para evaluar su potencial de producción y su capacidad para resistir a enfermedades y estreses ambientales o para garantizar su conservación a largo plazo. Existe por lo tanto un alto potencial para la aplicación de la biotecnología a partir de los notables avances globales en genética molecular, ingeniería genética y bioinformática, con el fin de desarrollar nuevas variedades ajustadas a situaciones de estrés biótico y abiótico, adecuadas a las necesidades de mitigación y adaptación al cambio climático. Asimismo se pueden producir mejoras sustanciales como la biofortificación del cultivo, mayor calidad del grano y productos finales con valor agregado. Continúa vigente la necesidad de fortalecimiento de los marcos regulatorios relativos al uso de la biotecnología, tanto en aspectos de seguridad ambiental y la salud humana, como en materia de derechos de propiedad y condiciones de acceso.

Palabras clave: biotecnología, fitomejoramiento, bioseguridad, estrés, transgénicos 


\section{ABSTRACT}

The objective of this paper is to present an overview of plant biotechnology application in Ecuadorian agriculture, taking the rice crop as a study case. Main used techniques in Latin America are described. So far, most of the research in Ecuador has been focused on tissue culture (anthers); little work has been done in rice germplasm characterization aiming to assess its productive potential and ability to endure diseases and environmental stresses or to secure its long term conservation. Therefore there is a substantial potential to apply biotecnology in light of noticeable global advances in molecular genetics, genetic engineering and bioinformatics, pursuing the development of novel varieties adjusted to biotic and abiotic stress conditions, fitted for climate change adjustment and mitigation. At the same time there are conspicuous improvements that can take place such as crop biofortification, higher grain quality, and final products with added value. There is still necessity to strengthen the regulatory frames related to biotechnology usage, both in environmental safety and human health, as well as property rights and entry conditions.

Keywords: biotechnology, plant breeding, biosafety, stress, transgenics

\section{INTRODUCCIÓN}

El arroz es uno de los cereales más extensamente cultivados a lo largo de un amplio rango de regiones geográficas, ecológicas y climáticas en el mundo. Junto con el maíz y el trigo, el arroz es clave para la seguridad alimentaria y económica de la mayoría de los países de la región (FAO, 2018). Es un alimento básico para más de la mitad de la población mundial (Travis et al. 2015) y en Latinoamérica constituye una de las principales fuentes de calorías (FAO, 2018). El consumo humano mundial promedio de arroz per cápita se sitúa en 57 kg/año; en la región es de 27 kg/año (Sanabria, 2018), aunque en países como Cuba el consumo per cápita puede superar los $70 \mathrm{~kg}$, mientras que en Ecuador el consumo se ubica en $53,2 \mathrm{~kg}$ por persona al año (El Universo, 2013) siendo el alimento que contribuye en mayor proporción al consumo diario de energía (Freire et al 2013).

En Ecuador es producido principalmente en las provincias de Guayas (67 \%) y Los Ríos (29\%) (Ministerio de Agricultura y Ganadería - MAG, 2015). En 2016 se cosecharon 366.194 ha con una producción total de 1.53 millones de toneladas y un rendimiento promedio de 4.19 t.ha ${ }^{-1}$ (MAGAP, 2018). La producción de arroz se destina al consumo 
interno, estando en manos de pequeños productores, con $50 \%$ de la cosecha realizada en fincas de menos de 20 ha (Corporación Financiera Nacional, 2018). Sin embargo, son muchas las amenazas para la estabilidad de la producción del cultivo, incluyendo las malezas, insectos plaga, enfermedades y la capacidad misma de las variedades para adaptarse a las áreas de cultivo y tener una productividad rentable.

Las variedades mejoradas de arroz permiten a los agricultores producir el cultivo en forma más eficiente y a un costo unitario más bajo (FAO, 2011). Por medio del mejoramiento genético se pueden lograr nuevas variedades que disminuyan los riesgos económicos del cultivo. Las nuevas variedades de arroz benefician también al medio ambiente, pues tienden a disminuir el uso de plaguicidas y reducen la presión para incorporar nuevas tierras a la producción de arroz.

Se han logrado avances notables en la obtención de nuevas variedades mediante el mejoramiento de germoplasma. El enfoque del Programa de Arroz en Ecuador, conducido por el Instituto Nacional de Investigaciones Agropecuarias (INIAP), se orienta al aumento de la productividad, resistencia genética a enfermedades, principalmente virus de la hoja blanca (RHBV), pudrición de la vaina (Sarocladium oryzae), tizón del tallo (Rhizoctonia solanı), quemazón (Pyricularia grisea), manchado del grano (complejo hongo-bacteria), y granos de alta calidad que tengan ventaja competitiva en los mercados y aceptación por parte de los consumidores. Es así como mediante métodos convencionales de mejoramiento genético y usando fuentes de diversidad genética aportadas por introducciones desde el Instituto Internacional de Investigaciones en Arroz (IRRI), Centro Internacional de Agricultura Tropical (CIAT), y más recientemente bajo convenios con el Fondo Latinoamericano de Arroz de Riego (FLAR). En Ecuador se han desarrollado materiales genéticos adaptados desde 1971 (Pérez et al. 2019).

La agricultura constantemente se enfrenta al desafío de proveer alimentos en calidad y cantidad suficientes para satisfacer la demanda de una población que seguirá creciendo y cuyo poder de compra continuará incrementándose. La aplicación de biotecnologías puede incrementar significativamente la eficiencia para alcanzarlo.

Este artículo tiene como objetivo hacer un balance de la aplicación de las biotecnologías en el mejoramiento del arroz, revisar brevemente los resultados más recientes obtenidos en este área del conocimiento, y las perspectivas actuales y futuras de su utilización en Ecuador. 


\section{REVISIÓN TEÓRICA}

Se entiende como biotecnología toda aplicación tecnológica que utilice sistemas biológicos y organismos vivos o sus derivados para la creación o modificación de productos o procesos para usos específicos (ONU, 1992). La biotecnología es la ciencia que tiene por objetivo el estudio de organismos vivos o sus partes para la obtención de bienes y servicios.

Las herramientas biotecnológicas actuales se usan masivamente en la producción de enzimas, probióticos, pigmentos, vitaminas, aminoácidos, potenciadores del sabor, aditivos y levaduras mejoradas para los procesos de transformación industrial de los alimentos, así como en la fortificación, el alargamiento de la vida útil y la mejora del sabor y la calidad nutritiva, reflejadas como mejores características organolépticas, químicas o fisicoquímicas (AESA, 2005).

Son muchos los aspectos de la industria agroalimentaria en que la biotecnología ha ganado espacios. Se ha convertido también en un importante instrumento para comprobar la autenticidad de los alimentos y de sus materias primas (AESA, 2005). Los ámbitos de la inocuidad, del control de compras de materias primas, o del apoyo a sistemas de identidad preservada, son algunas de las áreas en que la biotecnología se puede aplicar en la distribución y comercialización de los alimentos, entre muchas otras aplicaciones.

La biotecnología agrícola ofrece un amplio espectro de oportunidades para aumentar la productividad, entre ellas las técnicas de cultivo de tejidos, las técnicas avanzadas de biología molecular, la transformación genética, el análisis genómico asociado al mejoramiento genético y al diagnóstico de enfermedades, y la producción de bioplaguicidas.

Los continuos cambios en las demandas del sector arrocero y las predicciones de nuevas condiciones climáticas requieren la adaptación y mejoramiento del cultivo a través de la obtención de nuevas variedades (Nelson et al, 2009). Los avances en investigación en arroz y las herramientas genómicas desarrolladas en biotecnología los últimos años han permitido la modernización de la mejora de variedades, haciéndola dirigida y rápida.

En este orden de ideas, las aplicaciones biotecnológicas que se han implementado en el cultivo de arroz incluyen: 
Cultivo de Anteras: fue señalado por primera vez por Niizeki y Oono en 1968, siendo este el primer informe exitoso de la obtención de una planta haploide regenerada en cereales. El uso de la técnica de cultivo de anteras in vitro presenta algunas ventajas comparada con los métodos tradicionales de mejoramiento; sin duda, una de las mayores es la simplicidad del método. La técnica ha sido utilizada en especies cultivadas como trigo, arroz, cebada, maíz, y papa (Withers y Alderson, 1986). Como cada cruzamiento genera una planta híbrida $F_{1}$, cada grano de polen constituye una gameta diferente. Así, una población de plantas doble-haploides (DH) provenientes del cultivo de anteras, representará la variabilidad genética de la población $F_{1}$, siendo las plantas $\mathrm{DH}$ homocigotas genéticamente. Otras ventajas son la economía en el tiempo necesario para la obtención de líneas puras, lo cual reduce a su vez el tiempo en obtener las generaciones cuando se está procurando ampliar la diversidad en los reservorios genéticos; hay economía de recursos financieros y materiales, al no requerir grandes áreas de siembra, ni otros costos de producción; $y$, aumento de la eficiencia de selección tanto en caracteres cualitativos como cuantitativos, facilitando la selección de los genotipos superiores.

Entre las desventajas se puede mencionar una alta dependencia del genotipo. Los genotipos indica han mostrado poca respuesta a la inducción de callos, observándose la necrosis temprana de las anteras y un desarrollo pobre de los callos (Lentini, Martínez y Roca, 1997), mientras que los japónica de secano presentan generalmente bajo porcentaje de regeneración de plantas verdes (factible de superar si se utiliza el medio adecuado). Además, el costo inicial de equipamiento de un laboratorio de cultivo de anteras puede ser relativamente alto. Sin embargo, a mediano plazo, esta inversión puede ser recuperada si se considera la reducción de alrededor de $30 \%$ en costos de desarrollo de un material empleando cultivo de anteras versus el método de pedigrí solamente (Sanint et al. 1993). Esta dependencia genotípica de la respuesta in vitro ha obstaculizado la adopción amplia del cultivo de anteras de arroz como herramienta rutinaria en el mejoramiento. En otros cereales también se han encontrado diferencias genotípicas en la producción de plantas verdes en la aplicación práctica de la técnica (Guha-Mukherjee, 1973; Lentini, Martínez y Roca, 1997).

Variación Somaclonal: es un fenómeno que se presenta durante el cultivo in vitro, cuyo origen y naturaleza son diversas, quizá originada por mutaciones de punto (Bouharmont et al. 1991). Otra investigación señala que las variaciones somaclonales podrían deberse a la ocurrencia de rearreglos cromosomales (cambios de posición de secciones de cromosomas), metilación del ADN, o inserciones de transposones (Jain, 2001). 
Algunas de las modificaciones de caracteres pueden ser de interés agronómico, aunque pocas han sido aplicadas en el mejoramiento varietal. Existen dos maneras de aprovechar estas variaciones somaclonales. Primero, a través de la selección de la población regenerante a partir de cultivos celulares. La segunda forma implica la selección de líneas celulares que resultan resistentes a algún estrés de tipo biótico o abiótico. En arroz se ha usado esta última, para seleccionar materiales más tolerantes a condiciones de alta salinidad, toxicidad por aluminio, estrés por frío, y resistencia a enfermedades como piricularia (Araujo et al. 2001; Araujo et al. 2004; Torrealba et al. 2006).

Marcadores: Existen tres tipos de marcadores que se pueden emplear en el mejoramiento vegetal para la selección e identificación varietal: los marcadores morfológicos, los bioquímicos y los moleculares.

Los morfológicos son fáciles de observar, pero tienen como principal inconveniente que existe un bajo número de ellos; la mayoría son dominantes; puede haber problemas de epistasia (interacción génica en la cual un par de alelos inhibe la manifestación de otros pares); y su expresión no siempre es temprana en el desarrollo de la planta (PerezAlmeida, 2004).

Los marcadores bioquímicos, basados en la generación de patrones electroforéticos isoenzimáticos, se caracterizan por su simplicidad, mínima cantidad del material en estudio, bajo costo y una cobertura del genoma de 10-20 loci por especie, ausencia de epistasis e influencias ambientales. La expresión alélica es de tipo codominante, lo que permite establecer comparaciones entre especies, poblaciones de una misma especie, y detectar la presencia de híbridos e introgresión de genes. Entre sus desventajas se incluye un nivel bajo de polimorfismo al presentar pocos alelos por locus, especialmente cuando la base genética es estrecha. Otro aspecto a considerar es que las proteínas, siendo un producto de la expresión génica, pueden ser afectadas cualitativa y cuantitativamente en su nivel de expresión por factores ambientales (Perez-Almeida, 2004).

Para aumentar la eficiencia de la técnica ante este factor, deben identificarse los estados de desarrollo de la planta durante los cuales la proteína es estable. Además, al igual que con las proteínas de reserva, las isoenzimas pueden o no reflejar los cambios genéticos que ocurren en el ADN, además sólo un set de genes estructurales está representado en estas proteínas, es decir que sólo parte del genoma se puede evaluar. 
Los marcadores moleculares se basan en: a) la amplificación del ADN (o parte del mismo) por la reacción en cadena de la polimerasa (PCR), como en el caso de los ADN polimórficos amplificados al azar o RAPDs (Random Amplified Polymorphism DNA) (Williams et al. 1990), los microsatélites o SSR (secuencias simples repetidas) (Panaud et al. 1996), por ejemplo, o b) en la generación de sitios de corte en la secuencia del $A D N$, como en el caso de los polimorfismos de longitud de fragmentos de restricción o RFLPs (Restriction Fragment Length Polymorphisms) (Jena y Kochert, 1991), entre otros. Los productos de amplificación que representan polimorfismos genómicos tienen herencia mendeliana estricta. Los marcadores moleculares se caracterizan porque su detección es fácil y rápida, muchos son codominantes, hay ausencia de pleiotropismo y epistasia, la expresión es temprana, su distribución es homogénea en muchos casos y presentan un alto polimorfismo. Con la ayuda de marcadores moleculares, es posible identificar caracteres útiles de tolerancia o resistencia a los principales tipos de estrés biótico y abiótico en el germoplasma silvestre de arroz, hacer cruzamientos interespecíficos y seleccionar germoplasma respecto a estos caracteres útiles; su uso ha revolucionado el mejoramiento tradicional aportando herramientas genómicas, que pueden utilizarse en la selección asistida por marcadores moleculares para el desarrollo de cultivares. Estos marcadores son particularmente útiles para la incorporación de genes que están altamente influidos por el ambiente, y otros de difícil estudio como los que confieren resistencia a enfermedades, y para acumular múltiples genes para resistencia a patógenos específicos y plagas dentro del mismo cultivar (piramidización génica) (Perez-Almeida, 2004).

El uso de los marcadores moleculares en lo que se denomina selección por mejoramiento asistido (SAM) permite al fitomejorador el avance generacional más rápido, ya que a través del uso de PCR se puede detectar si el gen está presente en las líneas evaluadas en generaciones más tempranas durante el proceso de mejoramiento.

Trangénicos o ingeniería genética: Desde un punto de vista técnico, los cultivos genéticamente modificados (OGM) son plantas transformadas a nivel de su ADN mediante la inserción de un ADN foráneo, que se diferencian de su equivalente no transgénico solamente en la expresión del gen insertado, y representan una alternativa para lograr lo que de manera natural no se hubiera logrado (Escobar, 2013). No se puede dejar de mencionar el más importante desarrollo de la ingeniería genética de plantas, el Arroz Dorado. Este es un arroz modificado genéticamente para acumular en su embrión el precursor de la vitamina $A$, llamado provitamina A o $\beta$-caroteno, además de otros carotenos de importancia nutricional. Este $\beta$-caroteno es el que le otorga un 
característico y peculiar color dorado dándole su nombre (Al-Babili y Beyer, 2005; Bajaj y Mohanty, 2005; Schaub et al. 2005). El arroz dorado representa un suministro de $7 \mu \mathrm{g}$ $\beta$-caroteno por $\mathrm{g}$ de endospermo de arroz (Golden Rice 1) hasta unos $37 \mu \mathrm{g} / \mathrm{g}$ de arroz en el Golden Rice 2 (Paine et al. 2005; Al-Babili y Beyer 2005; Li et al. 2006). El enfoque transgénico consistió en conectar los eslabones faltantes en la ruta de biosíntesis de $\beta$ caroteno, vía metabólica que no existe de forma natural en el arroz. El Arroz Dorado se produjo por la introducción del gen que codifica para la fitoeno- sintasa de Narcissus, y del gen que codifica para la fitoeno-deshidrogenasa de Erwinia (Al-Babili y Beyer, 2005; Mayer, 2007) con el fin de modificar la ruta metabólica de producción de $\beta$-carotenos en el endospermo del arroz; logrando completar la única ruta metabólica entera que se haya insertado en una planta por medio de métodos de ingeniería genética, mostrando que era posible diseñar la ruta bioquímica completa. Inicialmente se desarrolló en cultivares de la subespecie japonica y más recientemente se ha trabajado en cultivares de la subespecie indica (Ye et al. 2000; Potrykus, 2001; Ahmad et al. 2011). Se han producido tres generaciones de Arroz Dorado, la primera en 1999 llamada prototipo ó GR (Golden Rice) (Ye et al. 2000; Mayer, 2007). La segunda se obtuvo en el 2003, que fue la primera línea mejorada de arroz dorado (SGR1) la cual presentaba niveles más altos de provitamina $\mathrm{A}$, y además los genes estaban bajo el control del promotor tejidoespecífico para endospermo de la glutelina (Potrykus, 2001; Mayer, 2007). En 2005 se presentó la tercera generación de arroz dorado ó SGR2, la cual produce 23 veces más provitamina A que la versión inicial, es decir $37 \mu \mathrm{g} / \mathrm{g}$ de provitamina A. Esta versión se diferencia de las anteriores por la utilización de genes de gramíneas como arroz o maíz para reemplazar el gen de la fitoeno sintasa de Narcissus pseudonercissus (Al-Babili y Beyer, 2005; Paine et al. 2005). El Arroz Dorado busca ser una fuente de vitamina A para poblaciones que no consumen la suficiente cantidad de esta vitamina, imprescindible en su dieta diaria, y de este modo contribuir a disminuir la avitaminosis en los países en vías de desarrollo. La investigación fue financiada por la Fundación Rockefeller, el Instituto Federal Suizo de Tecnología (Zurich), el programa Biotech de la Comunidad Europea y la Oficina Federal Suiza de Educación y Ciencia (Potrykus, 2001; Mayer, 2007).

De esta manera, podemos ver que la ingeniería genética juega un papel fundamental en el mejoramiento de las especies vegetales permitiendo la introducción de genes de interés, además de ampliar el reservorio genético existente.

Más recientemente está en curso una nueva era del mejoramiento genético por medio de las técnicas de edición génica que generan cambios precisos y controlados (edición) 
de las secuencias génicas a partir de un sistema de enzimas de restricción. Este sistema se espera que aporte una nueva revolución biotecnológica y contribuciones sustanciales al desarrollo de cultivos y alimentos. CRISPR (Clustered Regularly Interspaced Short Palindromic Repeats, o repeticiones palindrómicas cortas agrupadas y regularmente interespaciadas, por su traducción del inglés), funciona naturalmente como un sistema inmune adaptativo microbiano para protegerse de ADN exógeno (Mojica, Juez, y Rodríguez-Valera, 1993).

Fue descrito por primera vez en 1987 (Ishino et al. 1987) y se ha descubierto que puede facilitar la manipulación de genomas eucariotas, obteniendo cambios en sitios específicos del ADN para generar organismos con características deseadas (Ran et al. 2013).

Entre las principales aplicaciones de esta tecnología se destacan casos como la obtención de un arroz con alto contenido de amilosa, en el cual se utilizó el sistema CRISPR/Cas para generar mutaciones dirigidas en los genes SBEI y SBEII (Starch branching enzyme - enzimas de ramificación del almidón I y II) del arroz. Como resultado, se obtuvieron líneas con inserciones/deleciones en los genes SBEI y SBEII, favoreciendo el aumento en los contenidos de amilosa y almidón resistente, los cuales son considerados como beneficiosos para la salud humana (Sun et al. 2017).

El arroz ha sido seleccionado como un organismo modelo para el estudio de la biología de los cereales o gramíneas (Shimamoto y Kyozuka, 2002). Un organismo modelo se caracteriza por requerir fácil mantenimiento (no supone un gran costo tenerlos en el laboratorio o el campo); un ciclo biológico o de vida rápido (se requieren horas o meses para completar su ciclo de vida); alto número de descendientes; y un genoma sencillo o pequeño.

Además el arroz fue el primer cultivo en tener su genoma secuenciado completamente en sus dos subespecies más representativas: con $466 \mathrm{Mb}$ en arroz indica (Yu et al. 2002) y 420 Mb japónica (Goff et al. 2002). Como resultado, se han obtenido mapas genéticos, físicos y comparativos, la caracterización de varios genes y la secuencia completa de su genoma. Con estas herramientas se han apoyado y optimizado, conjuntamente con otras tecnologías, los procesos de mejoramiento de la especie y de otras relacionadas (Shimamoto y Kyozuka, 2002; Bajaj y Mohanty, 2005). 


\section{El Caso de Ecuador}

Mientras el cultivo de tejidos ya constituía una técnica estándar en casi todos los laboratorios biotecnológicos en América Latina, los marcadores moleculares y sobre todo las aplicaciones de tecnologías transgénicas estuvieron limitados por décadas a laboratorios grandes en países tecnológicamente avanzados en la región, como Argentina, Brasil y México (Wendt y Izquierdo, 2002), y luego Chile, Venezuela y Colombia.

En el caso de Ecuador, la investigación relacionada a biotecnología ha estado enfocada a la identificación de variabilidad genética en poblaciones biológicas, su selección y producción de variedades adaptadas (Wendt y Izquierdo, 2002). Las tecnologías de cultivo de tejidos están frecuentemente presentes en casi todos los laboratorios del país y también el uso de marcadores moleculares como los RAPDs es relativamente común.

La orientación de las investigaciones según los cultivos ha dependido del mandato y financiamiento de cada una de las instituciones. Las actividades del INIAP a través del Departamento Nacional de Recursos Fitogenéticos (DENAREF), el cual reviste alta importancia con respecto a la conservación de la biodiversidad del país, han sido financiadas mayormente por fondos públicos y se han concentrado en la conservación ex-situ e in-situ de los tubérculos andinos (Wendt y Izquierdo, 2002). Otros laboratorios del INIAP se han dedicado al fitomejoramiento de maíz, cacao, arroz y banano; mientras que las universidades, si bien financian su programa regular con fondos públicos o privados, tradicionalmente han tenido limitado el acceso para la realización de proyectos.

El INIAP ha desarrollado importantes trabajos de investigación referentes a la obtención de variedades de arroz utilizadas por los agricultores. Las más recientes son INIAP_FL Cristalino (INIAP_FL 1480) liberada en 2016 (El Telégrafo, 2016; INIAP, 2017) e INIAP_FL Arenillas (INIAP_FL 0202) en 2017 (INIAP, 2017b; 2017c). Estas variedades tienen tolerancia a ciertas enfermedades y plagas que atacan al cultivo, como el virus de la hoja blanca (RHBV), pudrición de la vaina (Sarocladium oryzae), tizón del tallo (Rhizoctonia solani), quemazón (Pyricularia grisea) manchado del grano (complejo hongo-bacteria), y sogata (Tagosodes oriziculus). Además, algunos agricultores utilizan las variedades conocidas como tradicionales, a las cuales se ha documentado la adaptación y tolerancia bajo condiciones de estrés biótico y abiótico en otras investigaciones (Roy et al. 2015), por lo cual su acervo genético está siendo recolectado 
activamente por el Programa de Arroz de INIAP para su estudio (Pérez-Almeida et al. 2019).

Con respecto a la técnica de cultivo de anteras, durante los años 2011-2012 se condujeron investigaciones en el INIAP con el fin de establecer la técnica y generar líneas doble haploides para ser evaluadas en el programa de arroz (INIAP, 2012), así como algunas tesis de grado (Arana, 2012). Sin embargo nuevamente se observó que el genotipo fue limitante para la obtención de líneas doble haploides en la etapa de regeneración.

Recientemente se publicó un estudio de la diversidad genética de los materiales del Programa de Arroz del INIAP utilizando marcadores moleculares microsatélites (SSR) donde se valoraron 76 genotipos, representando 13 variedades comerciales, 35 líneas en observación y 24 variedades tradicionales, por su variabilidad genética, utilizando además 4 testigos internacionales (Pérez-Almeida et al. 2019).

También se realizó un estudio de detección molecular del vector del virus de entorchamiento en arroz (RSNV - rice stripe necrotic virus) (Pérez-Almeida et al. 2018), mostrando una metodología sencilla para detectar la presencia del protista vector en el sistema radicular de plantas de arroz.

Dentro de los acuerdos internacionales más relevantes para la aplicación de la biotecnología figuran el Protocolo de Cartagena sobre Bioseguridad del Convenio de la Diversidad Biológica, adaptado en el año 2000, el Acuerdo sobre los Derechos de Propiedad Intelectual Relacionados al Comercio (ADPIC) de la OMC, aprobado en 1994, el mismo Convenio de la Diversidad Biológica del año 1993 y el Tratado Internacional sobre los Recursos Fitogenéticos para la Agricultura y Alimentación de la FAO, aprobado en el año 2001 (Wendt y Izquierdo, 2002).

La Constitución de la República del Ecuador (2008) afirma en su Art. 15 que "se prohíbe el desarrollo, producción, comercialización, importación, transporte, almacenamiento y uso de armas químicas, biológicas y nucleares, de contaminantes orgánicos persistentes altamente tóxicos, agroquímicos internacionalmente prohibidos, y las tecnologías y agentes bilógicos experimentales nocivos organismos genéticamente modificados perjudiciales para la salud humana o que atenten contra la soberanía alimentaria o los ecosistemas, así como la introducción de residuos nucleares y desechos tóxicos al territorio nacional". 
En el Art. 401.- Se declara al Ecuador libre de cultivos y semillas transgénicas. Excepcionalmente, y sólo en caso de interés nacional debidamente fundamentado por la Presidencia de la República y aprobado por la Asamblea Nacional, se podrán introducir semillas y cultivos genéticamente modificados. El Estado regulará bajo estrictas normas de bioseguridad, el uso y el desarrollo de la biotecnología moderna y sus productos, así como su experimentación, uso y comercialización. Se prohíbe la aplicación de biotecnologías riesgosas o experimentales.

El ambiente político reconoce y favorece la biotecnología como una herramienta útil para el desarrollo de la producción agrícola. En el país se conformó una Comisión de Bioseguridad integrada por representantes de los Ministerios del Ambiente, de Agricultura y Ganadería (INIAP, Agrocalidad, Dirección de semillas), de Comercio Exterior y de Salud Pública, para regular el tema de la bioseguridad. Deben tomarse las oportunidades para formar correctamente la opinión pública en base a informaciones científicas para evitar el establecimiento de mitos y prejuicios inadecuados, como ocurre en otros países de la región. Sin embargo, hay que demostrar de una forma transparente y entendible los potenciales riesgos y beneficios de estas tecnologías para generar realmente una masa crítica que disponga de una base de conocimientos para poder entender e interpretar las decisiones del gobierno en éste ámbito.

Sobre transgénicos el INIAP emitió sus criterios los cuales expresan en síntesis que el país no puede abstraerse de hacer investigación y lo más práctico y cercano sería utilizar eventos que ya están libres de patentes para incluirlos en sus programas de mejoramiento. Como se ha visto el uso a nivel comercial está prohibido por la Constitución.

\section{Perspectivas}

Existe un alto potencial en Ecuador para la aplicación de la biotecnología. Un factor importante es la alta biodiversidad del país, la cual aún no está suficientemente investigada y documentada. Se cuenta con personal capacitado y algunos laboratorios en instituciones públicas así como universidades para la realización de proyectos de investigación e impartir docencia. La aplicación de biotecnologías en este aspecto se enfocaría en la selección de características deseables mediante marcadores moleculares. Las aplicaciones actuales y potenciales de la biotecnología pueden darse en los ámbitos de la producción de materias primas y en la elaboración agroindustrial. La biotecnología también ha sido promovida como una herramienta de adaptación en casos como el desarrollo de variedades ajustadas a situaciones de estrés hídrico. 
En las últimas décadas la biotecnología ha permitido mejoras sustanciales en el sector agrícola como la biofortificación de cultivos y la resistencia a plagas, enfermedades y herbicidas, entre otros. En el caso de la industria alimentaria, la biotecnología ha intensificado su contribución en estas áreas a partir de los notables avances en genética molecular, ingeniería genética y bioinformática ocurridos en las tres últimas décadas (AESA, 2005).

La colaboración público-privada es fundamental para avanzar en el desarrollo y la aplicación de nuevas tecnologías adecuadas a las necesidades de mitigación y adaptación de la agricultura al cambio climático. Por otro lado, la introducción de las nuevas tecnologías demanda el fortalecimiento de los marcos regulatorios relativos a su uso, tanto en aspectos de seguridad con el medio ambiente y la salud humana, como en materia de derechos de propiedad y otras condiciones de acceso.

En el sector agrícola y de alimentos, los transgénicos han generado polémica a nivel local y mundial (Young, 2004; Inghelbrecht, Dessein y Van Huylenbroeck, 2014; Julio, 2014; Zenteno, 2015). Hay quienes sostienen que estos productos son un avance y que repercuten en una mejora de la alimentación humana; plantas más resistentes a plagas, enfermedades y herbicidas, posibilidad de incorporarles elementos nutritivos en beneficio de la salud pública. La ingeniería genética en alimentos podría ayudar a resolver la problemática de hambruna y desnutrición en el mundo. Sin embargo, existen grupos opuestos que argumentan principalmente efectos secundarios a la salud e impacto ambiental negativo, aunque aún no hay evidencias científicas contundentes en este aspecto.

La opinión científica establece que según como se regulen y del contexto en el cual se los utilice, los OGMs sí pueden ser una herramienta más para la disminución del impacto ambiental y la producción más eficiente (Young, 2004; Inghelbrecht, Dessein y Van Huylenbroeck, 2014; Julio, 2014; Zenteno, 2015). Los sectores con mayor potencial a ser beneficiados serían el industrial, salud, agrícola y extracción de recursos naturales. Empero, varios académicos especializados en ciencias sociales manifiestan que el uso de OGMs no beneficia a todos por igual, especialmente en el sector agrícola (Acosta y Martinez, 2014). El sector social más vulnerable a sufrir consecuencias negativas causadas por la introducción de OGMs es el conformado por pequeños agricultores. La utilización de productos biotecnológicos podría llevar a pequeños productores ecuatorianos a depender de compañías o intermediarios especializados en venta de OGMs o subproductos. Esto podría ocurrir como efecto de la pérdida de mano de obra debido a la tecnificación ocurrida por el uso de OGMs o a la falta de opciones de 
mercado entre pequeños agricultores. Consecuentemente, podría haber el riesgo de que se vaya a crear procesos de desigualdad a mediano y/o largo plazo creados por dependencia económica no regulada. Además, en términos culturales, los críticos a OGMs declaran que el mayor riesgo está en que su utilización vaya a afectar la relación ética evolutiva entre humano y naturaleza (Acosta y Martinez, 2014; Zenteno, 2015).

Empero, según sus promotores, la introducción de OGMs en Ecuador no tiene por qué seguir un desarrollo biotecnológico liderado por intereses comerciales corporativos (Zenteno, 2015). La biotecnología puede ser desarrollada en instituciones de investigación, formadas total o parcialmente con fondos públicos, y por tanto ser dirigida por el Estado (Gressel, 2010).

Es así que Yachay o Ciudad del Conocimiento se presenta como una opción de gran potencial para el futuro desarrollo de productos biotecnológicos en el Ecuador. Es de este modo que se puede optar por biotecnología moderna formulada con base a objetivos no comerciales y por tanto enfocar la producción de OGMs hacia sectores vulnerables (Zenteno, 2015). La idea a largo plazo en el Ecuador es crear cultivos con OGMs que sean de beneficio para productores de todo nivel. La visión es crear cultivos que sean resistentes a sequías, inundaciones, plagas o enfermedades; o de beneficio para el consumidor como ser mejor olor, color, sabor o mayor valor nutritivo. Sin embargo, la oportunidad para lograr dichos OGMs alternativos depende de si se otorga el apoyo adecuado a los actores con interés en crear y/o comercializar dichos productos para el beneficio social. Varias de estas opciones ya han sido desarrolladas, aunque sin poder ingresar al mercado (Zenteno, 2015). Esto se debe a los intereses de actores globales que tienen influencia legislaciones internacionales, tanto a favor como en contra de OGMs (Altman y Hasegawa 2012).

Utilizando toda esta información, la biotecnología podría cambiar el escenario del arroz en dos áreas principales: (1) protegiendo el cultivo contra estrés biótico y abiótico, (2) modificando el concepto de producción de mediante la obtención de materia prima de mayor valor agregado (galletas, masa congelada, pan de molde, pasta, almidones, plásticos biodegradables), o sencillamente aumentando la calidad del grano para satisfacer demandas del consumidor (Pérez-Almeida, 2004).

Adicionalmente, aunque el arroz no tiene mayor importancia para la exportación, el cultivo se encuentra en el segundo lugar (después del cacao) de la superficie cosechada en el país (MAG, 2019). Existe un déficit de semilla certificada en el país, razón por la cual aproximadamente un $70 \%$ de los productores (ESPAC - INEC, 2013) utiliza semilla 
reciclada, es decir, grano que se siembra por varios ciclos, pero que proviene inicialmente de variedades mejoradas (Pino, Aguilar y Cevallos, 2018). El potencial de rendimiento con semilla certificada y aplicando el nivel de tecnología adecuada es de alrededor de $10 \mathrm{Tm} / \mathrm{ha}$. En la realidad los niveles históricos del rendimiento muestran una tasa de aproximadamente $4 \mathrm{Tm} / \mathrm{ha}$, que, si bien no es de las más elevadas, a escala nacional, refleja una trayectoria estable (INIAP, 2015). La mayoría de productores, generalmente guardan su propia semilla o la adquieren en las piladoras, siendo una de las causas del bajo rendimiento en el país (SINAGAP, 2016).

La gran superficie cultivada con arroz (alrededor de 400 mil ha) y los problemas con plagas y enfermedades significan un gran potencial para la promoción del uso de semilla mejorada certificada (INIAP, 2015), ya que la baja utilización de semilla certificada (SINAGAP, 2016) ocasiona el incremento de malezas como el arroz rojo y arroz negro, que son de difícil erradicación y perjudican la calidad final del producto (Páez y Almeida, 1994). Sin embargo, el alto costo de estas semillas parece en el momento el factor limitante para una mayor aceptación. Primero habría que demostrar a los productores ventajas reales en la utilización de semilla certificada y mejorar el acceso a insumos, sobre todo a través de crédito (Pino, Aguilar y Cevallos, 2018). El principal limitante para el uso de la semilla certificada constituye la desconfianza en la calidad de la semilla ofertada en el mercado. La biotecnología puede intervenir en procesos de determinación de la huella genética de nuevos materiales mejorados y garantizar su propiedad intelectual.

\section{CONCLUSIONES}

La mayor parte de la investigación básica en biotecnología agrícola y sus avances se han enfocado a la aplicación del cultivo de anteras para desarrollar líneas homocigotas en menor tiempo y con mayor eficiencia, obstaculizada por la dependencia de la respuesta y los genotipos de arroz indica. Por otro lado se observan esfuerzos de caracterización del germoplasma disponible mediante uso de los marcadores moleculares. El país tiene un alto potencial para la aplicación de la biotecnología en este y otros cultivos, debido a su megabiodiversidad, la cual aún no está suficientemente investigada y documentada. Existe el personal capacitado y laboratorios en instituciones públicas y privadas. 


\section{REFERENCIAS BIBLIOGRÁFICAS}

Acosta, A. y Martinez, E. (2014). Transgénicos: Inconciencia de la Ciencia. Quito: Ediciones Abya-Yala.

Agencia Española de Seguridad Alimentaria (AESA). (2005). Informe Aplicaciones de la Biotecnología en Seguridad Alimentaria. Recuperado de http://www.aecosan.msssi.gob.es/AECOSAN/docs/documentos/publicaciones/s eguridad_alimentaria/biotecnologia.pdf

Ahmad, P., Ashraf, M., Younis, M., Hu, X., Kumar, A., Akram, N., Nudrat, A. y Al-Qurainy, F. (2011). Role of transgenic plants in agriculture and biopharming. Biotechnol Adv. 30(3),524-40. doi: 10.1016/j.biotechadv.2011.09.006.

Al-babili, S. y Beyer, P. (2005). Golden rice - five years on the road - five years to go? Trends in Plant Science 1012(12), 565-573.

Altman, A. y Hasegawa, P.M. (2012). Introduction to plant biotechnology 2011: Basic aspects and agricultural implications. Plant Biotechnology and Agriculture xxix-xxxviii. doi:10.1016/B978-0-12-381466-1.00050-X.

Arana Vera, L.P. (2012). Cultivo in vitro de anteras en arroz Oryza sativa L para inducir plantas doble haploides homocigóticas. (Tesis de Grado). Universidad Tecnica de Babahoyo. Facultad de Ciencias Agropecuarias. Ecuador.

Araújo, L.G, Prabhu, A.S., Filippi, M.C., Chaves, L.J. (2001). RAPD analysis of blast resistant somaclones from upland rice cultivar IAC 47 for genetic divergence. Plant Cell, Tissue and Organ Culture 67(2), 165-172.

Araújo, L.G. , Prabhu, A.S., Arraes-Pereira, P.A. (2004). RAPD marker linked to a gene conferring resistance to race IB-9 of Pyricularia grisea in somaclones of the rice cultivar Araguaia. Plant Cell, Tissue and Organ Culture 78(2), 151-158.

Bajaj, S. y Mohanty, A. (2005). Recent advances in rice biotechnology-towards genetically superior transgenic rice. Plant Biotechnology Journal 3(3), 275307. doi: 10.1111/j.14677652.2005.00130.x

Berman, J., Zhu, C., Pérez-Massot, E., Arjó, G., Zorrilla López, U., Masip, G., Christou, P. (2013). Can the world afford to ignore biotechnology solutions that address food insecurity?. Plant Molecular Biology 83(1-2),5-19. 
Bouharmont, J., Dekeyser, A., VanSinJan, V., and Dogbe, Y.S. (1991). Application of somaclonal variation and in vitro selection to rice improvement. En: G.S. Khush (Ed.) Rice genetics II: Proceedings of the second International Rice Genetics Symposium. (pp. 271-278). Los Baños, Filipinas: IRRI.

Corporación Financiera Nacional. (2018). Ficha sectorial: Arroz. Subgerencia de Análisis e Información. Recuperado de: https://www.cfn.fin.ec/wpcontent/uploads/2018/04/Ficha-Sectorial-Arroz.pdf

El Telégrafo. (2016). Lanzan nueva variedad de arroz más resistente y de mayor rendimiento.

Recuperado

de:

https://www.eltelegrafo.com.ec/noticias/economia/4/el-iniap-presentara-aproductores-una-nueva-semilla-de-arroz.

El Universo. (2013). Un promedio de 117 libras de arroz al año consume cada ecuatoriano. (19 de Septiembre de 2013). Recuperado de: https://www.eluniverso.com/noticias/2013/09/19/nota/1462276/promedio-117libras-arroz-ano-consume-cada-ecuatoriano

Escobar, J.D. (2013). Biotecnología, bioseguridad y agricultura. En: C. Paz y Miño. (Ed). Transgénicos una cuestión científica. (pp. 69-74). Quito, Ecuador: Editorial de la Universidad de las Américas.

FAO. (2018). Seguimiento del mercado del arroz de la FAO Abril. Recuperado de: http://www.fao.org/economic/est/publicaciones/publicaciones-sobre-elarroz/seguimiento-del-mercado-del-arroz-sma/es/

FAO. (2011). Ahorrar para crecer. Guía para los responsables de las políticas de intensificación sostenible de la producción agrícola. Recuperado de: http://www.fao.org/3/l2215S/i2215s.pdf

Freire, W. B. Ramírez, M.J., Belmont, P., Mendieta, M.J., Silva, M.K., Romero, N. et al...y Monge R. (2013). Resumen Ejecutivo Tomo I. Encuesta Nacional de Salud y Nutrición del Ecuador. ENSANUT-ECU 2011-2013. Ministerio de Salud Pública /Instituto nacional de Estadística y Censos. Quito Ecuador.

Guha-Mukherjee, S. (1973). Genotypic differences in the in vitro formation of embryoids from rice pollen. J. Exp. Bot. 24(1), 139-144.

Gresel, J. (2010). Needs for and environmental risks from transgenic crops in the developing world. New Biotechnology 27(5),522-7. 
Goff, S.A., Ricke, D., Lan, T.H., Presting, G., Wang, R., Dunn, M., y Briggs, S. (2002). A Draft Sequence of the Rice Genome (Oryza sativa L. ssp. japonica). Science 296 (5565),92-100.

INEC - ESPAC. (2013). Superficie y Producción Agropecuaria. Recuperado de: https://www.ecuadorencifras.gob.ec/estadisticas-agropecuarias-2/

INIAP. (2017a). INIAP cuenta con la nueva variedad de arroz Cristalino que produce hasta $50 \%$ más que otras variedades. Recuperado de: http://www.iniap.gob.ec/pruebav3/vicepresidente-jorge-glas-iniap-cuenta-con-lanueva-variedad-de-arroz-cristalino-que-produce-hasta-50-mas-que-otrasvariedades/

INIAP. (2017b). INIAP liberará nueva variedad de arroz de alto rendimiento "INIAP FL Arenillas". Recuperado de: http://www.iniap.gob.ec/pruebav3/iniap-liberaranueva-variedad-de-arroz-de-alto-rendimiento-iniap-fl-arenillas/

INIAP. (2017c). En la provincia de EI Oro el INIAP realiza la liberación de la nueva variedad de arroz “INIAP FL Arenillas". Recuperado de: http://www.iniap.gob.ec/pruebav3/en-la-provincia-de-el-oro-el-iniap-realiza-laliberacion-de-la-nueva-variedad-de-arroz-iniap-fl-arenillas/

INIAP. (2015). Producción de semillas categoría certificada para el Proyecto Nacional de Semillas de Agrocadenas Estratégicas del MAGAP. Recuperado de: $\quad$ https://www.iniap.gob.ec/pruebav3/wpcontent/uploads/2019/04/Proyecto\%20Producci\%c3\%b3n\%20de\%20Semillas.p df

INIAP. (2012). Cultivo in vitro de anteras de arroz Oryza sativa $\mathbf{L}$ para inducir plantas doble haploides homocigóticas. Recuperado de http://repositorio.iniap.gob.ec/bitstream/41000/1924/1/iniapls4.pdf

INIAP. (2007). Manual del cultivo de arroz. No. 66. 5-35 p.

Inghelbrecht, L., Dessein, J., y Van Huylenbroeck, G. (2014). The non-GM crop regime in the EU: How do Industries deal with this wicked problem? NJAS Wageningen Journal of Life Sciences, 70, 103-112. https://doi.org/10.1016/j.njas.2014.02.002

Ishino, Y., Shinagawa, H., Makino, K., Amemura, M., y Nakata, A. (1987). Nucleotide sequence of the iap gene, responsible for alkaline phosphatase isozyme 
conversion in Escherichia coli, and identification of the gene product. Journal of Bacteriology 169(12), 5429-5433.

Jain, S. (2001). Tissue culture-derived variation in crop improvement. Euphytica $118(2), 136-166$.

Jena, K.K. y Kochert, G. (1991). Restriction fragment length polymorphism analysis of CCDD genome species of the genus Oryza L. Plant Mol Biol. 16(5),831-9.

Julio, G. (2014). Biotecnología moderna en los alimentos actuales y del mañana. $J$ Selva Andina Biosph. 2(1), 23-29.

Lentini, Z., Martínez, C. y Roca, W. (1997). Cultivo de anteras de arroz en el desarrollo de germoplasma. Cali, CO: Centro Internacional de Agricultura Tropical (CIAT).

Li, A.H., Zhang, Y.F., Wu, C.Y., Tang, W., Wu, R., Dai, Z.Y., y Pan, X.B. (2006). Screening for and genetic analysis on T-DNA-inserted mutant pool in rice. Acta Genetica Sinica 334(2), 319-329.

MAG (Ministerio de Agricultura y Ganadería). (2019). Cifras agroproductivas. Recuperado de: http://sipa.agricultura.gob.ec/index.php/cifras-agroproductivas

MAG (Ministerio de Agricultura y Ganadería). (2015). Boletín situacional de arroz. Coordinación General del Sistema de Información Nacional. Quito, p.6.

Mayer, J. (2007). Golden rice, Golden crops, Golden prospects. Revista Colombiana de Biotecnología 9(1), 22- 34.

Mojica, F. J., Juez, G., y Rodríguez-Valera, F. (1993). Transcription at different salinities of Haloferax mediterranei sequences adjacent to partially modified Pstl sites. Molecular Microbiology 9(3), 613-621.

SINAGAP (Sistema de Información Nacional de Agricultura y Pesca). (2016). Rendimientos de arroz en cáscara en el Ecuador, primer cuatrimestre del 2015. Recuperado de https://docplayer.es/41869282-Rendimientos-de-arroz-encascara-en-el-ecuador-primer-cuatrimestre-del-2015.html

Nelson, G. C., Rosegrant, M.W., Koo, J., Robertson, R., Sulser, T., Zhu,T., et al. y Lee, D. (2009). Cambio climático: El impacto en la agricultura y los costos de adaptación. Washington D.C., USA: Instituto Internacional de Investigación sobre Políticas Alimentarias IFPRI. Recuperado de: 
http://www.fao.org/fileadmin/user_upload/AGRO_Noticias/docs/costo\%20adapt acion.pdf

Niizeki, H. and K. Oono. (1968). Induction of haploid rice plant from anther culture. Proc. Jpn. Acad. 44(6),554-557.

Organización de las Naciones Unidas (ONU). (1992). Convenio sobre la Diversidad Biológica. Recuperado de https://www.cbd.int

Páez N. O.E. y N. C. Almeida P. (1994). Control Integrado de malezas en arroz bajo riego en el estado Portuguesa. Agronomía Trop. 44(2), 245-262.

Paine, J.A., Shipton, C.A., Sunandha, C., Howells, R.M., Kennedy, J.M., Vernon, G., y Drake, R. (2005). Improving the nutritional value of Golden Rice through increased pro-vitamin A content. Nature Biotechnology 23(4), 482-487.

Panaud, O., Chen, X., y McCouch, S.R. (1996). Development of microsatellite markers and characterization of simple sequence length polymorphism (SSLP) in rice (Oryza sativa L.). Mol Gen Genet. 252(5), 597-607.

Perez-Almeida, Iris. (2004). Aplicaciones Biotecnológicas en el Mejoramiento del Arroz. Revista Digital CENIAP HOY N 6, septiembre-diciembre 2004. Maracay, Aragua, Venezuela. URL: www.ceniap.gov.ve/ceniaphoy/articulos/n6/arti/perez_almeida_i/arti/perez_alme ida_i.htm

Pérez-Almeida, I., Celi, R., Paz, L. y Ramos, B. (2018). Detección molecular de Polymyxa graminis en plantas de arroz afectadas con la enfermedad del "entorchamiento". En: Agrociencias, Investigación y Sostenibilidad. I Convención Científica Internacional de la Universidad Técnica de Manabí. (pp. 42-54). Portoviejo, Ecuador: UTM.

Pérez-Almeida, I., Celi, R., Sánchez, F., Paz, L. y Ramos, B. (2019). Assessment of molecular genetic diversity of Ecuadorian rice cultivars using simple sequence repeat markers. Bioagro 31(1), 3-12.

Pino S. L., Aguilar H.R., Cevallos, L.E. (2018). Evaluación beneficio-costo del programa estatal de multiplicación de semilla de arroz 2015-2016. Revista Espacios 39(16), 15-25.

Potrykus, I. (2001). Golden rice and beyond. Plant Physiol 125(3),1157-1161 
Ran, F.A., Hsu, P.D., Wright, J., Agarwala, V., Scott, D.A. y Zhan, F. (2013). Genome engineering using the CRISPR-Cas9 system. Nature Protocols 8, 2281-2308. doi.org/10.1038/nprot.2013.143

Roy, S., Banerjee, A., Mawkhlieng, B., Misra, A.K., Pattanayak, A., Harish, G.D. y Bansal, K.C. (2015). Genetic diversity and population structure in aromatic and quality rice Oryza sativa L. landraces from North Eastern India. PLOS ONE 10(6), e0129607.

Sanabria, Y. (2018). Genética y mejoramiento del cultivo en América Latina. En: Libro de Memorias IV Congreso Internacional de Biotecnología y Biodiversidad (CIBB 2018). (p.55). Guayaquil, Ecuador: CIBB-ESPOL.

Sanint, L.R., Martinez, C.P., Ramirez, A. y Lentini, Z. (1993). Rice anther culture versus conventional breeding: a cost/benefit analysis. En: Trends in CIAT commodities. Issue 128. Recuperado de http://agris.fao.org/agrissearch/search.do?recordID=QT9500071

Schaub, P., Al-Babili, S. y Drake, R. (2005). Why is Golden Rice golden (Yellow) instead of red? Plant Physiology 138(1), 441-450.

Shimamoto, K. y Kyozuka, J. (2002). Rice as a model for comparative genomics of plants. Annual Reviews 53(1), 399-419.

Sun, Y., Jiao, G., Liu, Z., Zhang, X., Li, J., Guo, X. y Xiu, L. (2017). Generation of highamylose rice through CRISPR/Cas9-mediated targeted mutagenesis of starch branching enzymes. Frontiers in Plant Science 8(1), 298.

Travis, A.J., Norton, G.J., Datta, S., Sarma, R., Dasgupta, T., Savio, F.L., y Price A.H. (2015). Assessing the genetic diversity of rice originating from Bangladesh, Assam and West Bengal. Rice 8(1), 35.

Young, T. (2004). Organismos Genéticamente Modificados y Bioseguridad: Un documento de antecedentes destinado a responsables de la toma de decisiones y otros interesados para ayudarles en la consideración de los asuntos relativos a los OGM (en línea). UICN (Unión Mundial para la Naturaleza). Consultado 01 Jul. 2011. Recuperado de: http://data.iucn.org/dbtwwpd/edocs/PGC-001-Es.pdf 
Torrealba, G., Salazar, E., Álvarez, R., Delgado, N., Figueroa, R., Moreno, O., et al. Gamboa, C. (2006). Variación somaclonal en seis genotipos de arroz. Agronomía Trop. 56(4), 585-591.

Wendt, J. y Izquierdo, J. (2002). Manejo y gestión de la biotecnología agrícola apropiada para pequeños productores: estudio de caso Ecuador. Fundación REDBIO Internacional con el apoyo de la Oficina Regional de la FAO para América Latina y el Caribe. Recuperado el 01 de agosto de 2019 de http://www.fao.org/tempref/GI/Reserved/FTP_FaoRlc/old/prior/segalim/prodalim /prodveg/ecuador.pdf

Williams, J.G., Kubelik, A.R., Livak, K.J., Rafalski, J.A., y Tingey, S.V. (1990). DNA polymorphisms amplified by arbitrary primers are useful as genetic markers. Nucleic Acids Res. 18 (22), 6531-6535.

Withers, L. y Alderson, P.G. (1986). Plant tissue culture and its agricultural applications. Londres: Butterworths.

Ye, X., Al-Babili, S., Kloeti, A., Zhang, J., Lucca, P., Beyer, P. y Potrykus I. (2000). Engineering the provitamin A (beta-carotene) biosynthetic pathway into (carotenoid-free) rice endosperm. Science 287 (5451), 303-305.

Yu, J., Hu, S., Wang, J., Wong, G.K., Li, S., Liu, B., y Yang, H. (2002). A draft sequence of the rice genome (Oryza sativa L. ssp. indica). Science 296 (5565), 79-92.

Zenteno, J. (2015). El reenfoque de la biotecnología en el Ecuador: influencia y visión de un nuevo grupo de poder. Proyecto 'Gobernanza Ambiental en América Latina y el Caribe: Desarrollando Marcos para el Uso Sostenible y Equitativo de los Recursos Naturales. ENGOV. Oslo, Noruega. Recuperado de http://www.engov.eu/documentos/policy_brief/2015_PolicyBrief5_ES.pdf 